\title{
Il patriota e il vaudeville. Teatro, pubblico e potere nella Parigi della Rivoluzione.
}

\section{Michel Biard}

\section{(2) OpenEdition \\ 1 Journals}

\section{Édition électronique}

URL : https://journals.openedition.org/ahrf/1039

DOI : 10.4000/ahrf.1039

ISSN : 1952-403X

Éditeur :

Armand Colin, Société des études robespierristes

\section{Édition imprimée}

Date de publication : 1 mars 2001

Pagination : 128-129

ISSN : 0003-4436

\section{Référence électronique}

Michel Biard, «Il patriota e il vaudeville. Teatro, pubblico e potere nella Parigi della Rivoluzione. »,

Annales historiques de la Révolution française [En ligne], 323 I janvier-mars 2001, mis en ligne le 21 avril 2004, consulté le 23 avril 2022. URL : http://journals.openedition.org/ahrf/1039 ; DOI : https://doi.org/ 10.4000/ahrf.1039

Ce document a été généré automatiquement le 23 avril 2022.

Tous droits réservés 


\title{
Il patriota e il vaudeville. Teatro, pubblico e potere nella Parigi della Rivoluzione.
}

\author{
Michel Biard
}

\section{RÉFÉRENCE}

Erica Joy Mannucci, Il patriota e il vaudeville. Teatro, pubblico e potere nella Parigi della Rivoluzione, Naples, Vivarum, 1998, 539 p.

1 En dépit d'un titre qui peut laisser penser à une étude centrée avant tout sur les seuls vaudevilles, l'ouvrage d'Erica Joy Mannucci a pour ambition d'évoquer la scène parisienne dans son ensemble et tous les genres de pièces qu'elle accueille. La plupart des chapitres sont d'une facture très classique et forment une synthèse utile pour le public italien, même si pour les amateurs du théâtre révolutionnaire il y a là peu de nouveautés (à l'exception, heureuse, des chapitres 5 et 6).

2 L'ouvrage s'ouvre avec le débat, antérieur à la Révolution, sur la fonction du théâtre comme école de la vertu ou école du vice. Anathèmes portés par l'Église, affrontements consécutifs aux écrits de Jean-Jacques, visions futuristes de Mercier pour son Paris de l'an 2440 (où la Cité compte un théâtre d'État érigé au rang d'école publique de la morale et du bon goût), développement progressif du théâtre populaire en marge de la scène privilégiée, élargissement des publics, tout est évoqué en un premier chapitre bien mené qui, tout naturellement, conduit le lecteur à la vie théâtrale parisienne de 1789 à 1792. Les salles (anciennes et nouvelles), le répertoire, le public, les aspects économiques (prix des billets, coûts de production) font l'objet d'un chapitre entier, cependant que sont aussi évoqués les débats sur la censure, l'émancipation des comédiens et la question cruciale de la liberté des théâtres. Le chapitre 4, pour sa part, livre davantage une énumération des divers genres, appuyée sur des exemples, qu'une véritable analyse du répertoire. Par contre, les deux chapitres suivants sont beaucoup 
plus novateurs. À l'aide d'un corpus d'une centaine d'œuvres, créées et/ou jouées en 1793 et dans le premier semestre de 1794, Erica Joy Mannucci analyse un nombre important de thèmes plus passionnants les uns que les autres, notamment la vision du soldat français sur les scènes parisiennes. Au-delà des pièces connues qui louent la mémoire des enfants héros (Bara et Viala célébrés au printemps et à l'été 1794), apparaissent des textes qui relatent la vie et la mort du simple militaire, ce quotidien qui voit par exemple Sans-Peur et $L a$ Tulipe chanter les louanges du vin, liquide qui donne sang froid et courage avant la bataille, liquide considéré comme «une des productions les plus précieuses du territoire français», vin de l'amitié et de la fraternité, vin que l'on offre à l'occasion au déserteur autrichien! Le soldat est évoqué dans ses rapports avec les autorités qui apportent la lumière tout autant que les consignes à respecter (au volontaire qui entend dans un discours «conception nationale» au lieu de Convention nationale, il est répondu que ce devrait être ainsi puisque c'est la Nation qui a conçu la Convention), mais aussi dans ses rapports avec les civils et ici, bien entendu, l'amour est au premier plan. La réputation française n'est plus à faire, à en croire les auteurs de théâtre, et lorsque les soldats quittent le village frontalier où ils séjournaient, «le ragazze sono tristi»... avec les soldats de la République disparaissent la gaieté et la tendresse (Le poste évacué de Deschamps). Du militaire au civil, le pas est vite franchi et Erica Joy Mannucci nous conduit alors vers une vie quotidienne qui, envahie par le politique, n'en reste pas moins intimiste. La parfaite famille républicaine, le bon père de famille, mais aussi le divorce, sont autant de thèmes qui sont analysés aux côtés de l'irruption du tutoiement républicain (La parfaite égalité ou les tu et toi, Les Vous et le toi, Le Sourd guéri ou les tu et les vous... ).

Après un chapitre consacré au retour insidieux de la censure et à l'emprisonnement de certains hommes de théâtre en 1793-1794, ainsi qu'au regain des débats sur la fonction civique du théâtre (Chénier, Maréchal, Cloots, Boissy d'Anglas, etc.), l'auteur nous propose de suivre les voies ouvertes par Cesare Segre (Teatro e romanzo. Due tipi di comunicazione letteraria) et de comprendre le théâtre en Révolution comme un genre particulier de communication, de médiation. Rapports entre pouvoir central, Commune de Paris et "peuple-public ", formes de communication entre auteurs, acteurs et spectateurs sont passés au crible de façon convaincante, même si l'on peut se demander dans quelle mesure certains schémas par trop compliqués ne servent pas qu'à «enfoncer des portes ouvertes»?

Pour clore cette appréciable synthèse, l'auteur fournit environ 25 pages de bibliographie (et de listes d'œuvres) et donne en appendice à ses lecteurs italiens le texte de deux pièces: L'Intérieur d'un ménage républicain (de Chastenet) et Le Poste évacué (deDeschamps). Gageons que le lecteur français saura lui aussi y trouver son plaisir. 